\title{
Avasküler nekrozda radyolojik değerlendirme
}

\author{
Radiologic evaluation of avascular necrosis
}

\author{
Fatih Arslanoğluํㅜ Ömer Serdar Hakyemez ${ }^{1}$, Alperen Öztürk ${ }^{2}$
}

\author{
${ }^{1}$ İstanbul Medipol Üniversitesi, Ortopedi ve Travmatoloji Anabilim Dalı, İstanbul \\ ${ }^{2}$ Istanbul S.B.Ü., Okmeydanı E.A.H., Prof. Dr. Cemil Taş̧̧ı̆̆lu Şehir Hastanesi, Ortopedi ve Travmatoloji Kliniği, İstanbul
}

\begin{abstract}
Avasküler nekroz femur başında iskemik yapısal hasara neden olarak ilerleyici dejeneratif eklem hastalığına neden olan bir durumdur. Eklem kıkırdağı çökmeden erken evrede hastalığın teşhis edilebilmesi, eklemin ve normal eklem fonksiyonunun korunabilmesi için önem taşımaktadır. Bu amaçla erken evre hastalığın tanısının konulmasında en sık kullanılan ve altın standart tanı yöntemi manyetik rezonans görüntülemedir. Bununla birlikte, diğer görüntüleme yöntemleri hastalığın tedavisinin planlaması, prognozunun belirlenmesi ve takiplerinin yapılmasında kullanılmaktadır. Bu yazıda en sık görülen lokalizasyon olan femur başı avasküler nekrozu üzerinden hastalığın radyolojik görüntüleme özelliklerine değinilmiştir.
\end{abstract}

Anahtar sözcükler: avasküler nekroz; radyoloji; hilâl bulgusu; çift çizgi bulgusu; prognoz; femur başı

\begin{abstract}
Avascular necrosis causes ischemic structural damage in the femoral head which leads to progressive degenerative joint disease. Early diagnosis before the joint cartilage collapse is important for preserving the normal joint function. For this purpose, magnetic resonance imaging is the most common and gold standard diagnostic method used in the diagnosis of early stage disease. However, other imaging methods are used in planning the treatment of the disease, determining its prognosis and following up. In this article, radiological imaging features of the disease are discussed through avascular necrosis of the femoral head, which is the most common localization.
\end{abstract}

Key words: avascular necrosis; radiology; crescent sign; double line sign; prognosis; femoral head
A vasküler nekroz (AVN) kemiğin iskemik olarak hasar görmesini ifade eder ve ilerleyici bir şekilde subkondral bölgede kemik hücrelerinin ölümü ile sonuçlanır. Bu durum eklem kıkırdağında kırık ve çökmeye neden olarak kalça ekleminde artroza neden olabilir. Hastalı̆̆ın radyolojik değerlendirmesi sadece tanı koyulmasına değil; hastalığın evrelendirilmesine, çökme öncesi aşamaların tanınmasına, prognozun tahmin edilmesine, tedavi planlamasına ve tedavi sonrası takiplerin yapılmasına olanak sağlar. ${ }^{[1]}$ AVN en sık femur başında görülmekle birlikte vücutta farklı lokalizasyonları etkileyebilmekte ve farklı etiyolojik nedenlere bağlı olarak görülebilmektedir. ${ }^{[2]}$ Bununla birlikte etiyolojiden ve lokalizasyondan bağımsız olarak görüntülemede AVN'ye bağlı tipik bazı bulgular görülür. Radyolojik değerlendirmede en sık radyografi, manyetik rezonans (MR) görüntüleme, bilgisayarlı tomografi $(B T)$ ve kemik sintigrafisi kullanılmaktadır. Erken evre lezyonların değerlendirilmesinde MR ve kemik sintigrafisi daha değerliyken, ileri evrelerde subkondral kırık ve çökmeyi değerlendirmek için radyografi ve BT ön plana çıkmaktadır. ${ }^{[3]}$

\section{RADYOGRAFIK DEĞERLENDIRME}

Her ne kadar MR ve nükleer tıp hibrid teknikleri gibi yöntemler hastalığın erken evresinin değerlendirilmesinde daha net bilgiler verse de, hastalığın tüm evrelerinde ilk değerlendirme radyografik değerlendirme ile başlar. ${ }^{[2]}$ Frontal ve lateral "frog leg (kurbağa bacağı pozisyonu)" grafiler tanısal doğruluğu artırmak için zorunludur. Radyografik bulguların erken evrede duyarlılığı düşüktür ve klinik bulgular ortaya çıktıktan sonraki 3-6 aya kadar herhangi bir radyografik bulgu tespit edilemeyebilir. ${ }^{[4,5]}$ Bununla birlikte hastalığın daha ileri evrelerinde radyografi bulguları belirgindir ve ek radyolojik görüntüleme ihtiyacını azaltabilir. ${ }^{[5]}$

- İletişim adresi: Op. Dr. Fatih Arslanoğlu, İstanbul Medipol Üniversitesi Ortopedi ve Travmatoloji Anabilim Dalı; Göztepe, Metin Sk. No:4, 34214 Bağcılar, İstanbul Tel: 0507 - 9405388 e-posta: dr.arslanoglufatih@gmail.com

- Geliș tarihi: 15 Eylül $2020 \quad$ Kabul tarihi: 30 Eylül 2020 
Tablo 1. Avasküler nekrozda görülen radyolojik bulgular
- Femur başında yamalı skleroz
- Kresentik subkondral lusensi
- Eklem yüzeyinde kollaps
- Eklem yüzeyinde fragmantasyon
- Eklem aralığında daralma
- Asetabular subkondral skleroz
- Osteofitler

AVN'de radyografik olarak yeterince özgül olmayan birçok radyolojik bulgu görülebilmektedir (Tablo 1 ). Bununla birlikte eklem yüzeyinin hemen altında görülen hilâl bulgusu (kresentik subkondral radyolusensi, crescent sign), femur başı avasküler nekrozu için patognomonik kabul edilmektedir. ${ }^{[6]}$ Hilâl bulgusu eklem yüzeyinde çökmeyle sonuçlanabilecek bir kırığı işaret eder ve avasküler nekrozda kötü prognostik faktördür. En iyi frog leg (kurbağa bacağı pozisyonu) kalça grafisinde görülür (Şekil 1).

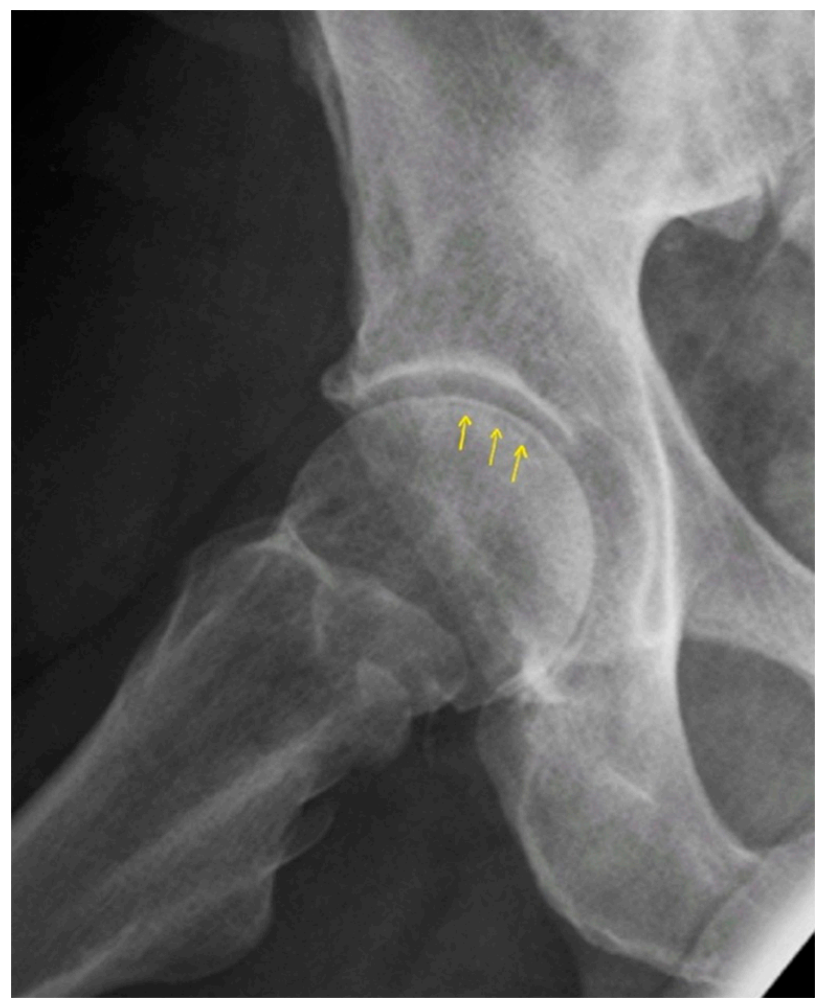

Şekil 1. Hilâl bulgusu (crescent sign) en iyi frog leg lateral grafide görülebilir (sarı oklar).
AVN'de radyografik bulgular kullanılarak yapılan Ficat-Arlet sınıflaması en yaygın kullanılan sınıflamadır ve daha sonra radyografik bulgu vermeyen dönemleri de içerecek şekilde modifiye edilmiştir. ${ }^{[7]}$ Evre 0: Radyografinin ve kliniğin normal olduğu dönemdir. Bir kalçasında AVN saptanan hastanın diğer kalçasında herhangi bir bulgu yoksa evre 0 denilebilir. Evre 1: Kalça ağrısının olduğu ancak radyografide herhangi bir bulgu saptanmayan rezorptif aşamayı temsil eden evredir. (Bu evrede MR ve sintigrafi bulguları pozitif olabilir.) Evre 2: Femur başı şeklinin bozulmadığı ve eklem aralığının korunduğu çökme öncesi tamir aşamasını temsil eder. Diffüz artmış porozite, kistik değişiklikler şeklinde demineralizasyon alanları ve yamalı skleroz görülür. Subkondral kistler görülmez. Evre 3: Femur başının erken çökmesini ve düzleşmesini temsil eden evredir. Eklem yüzeyinin hemen altında kırık çizgisini temsil eden lineer subkondral lusensi (hilâl belirtisi) bu evrede görülür. Eklem boşluğu korunmuştur. Evre 4: Femur başının düzgün konveks kontürünün kaybı ve düzleşmesi, femur başının çökmesi ve ağır kollapsı; eklem aralığının daralması, marjinal osteofit oluşumu ve subkondral kist formasyonu ile birlikte progresif dejeneratif eklem hastalığına giden süreci oluşturur. Sklerotik alanlarda kistik lezyonlar görülebilir ve kötü prognoz ile ilişkilidir. ${ }^{[8]}$

\section{MANYETIK REZONANS (MR) GÖRÜNTÜLEME}

AVN tanısında MR görüntüleme altın standart görüntüleme yöntemidir. Duyarlılı̆̆ ve özgüllüğü yaklaşık $\% 99$ 'dur ${ }^{[9]}$ ve osteonekrozun tüm evrelerinde pozitiftir. MR'nin esas rolü radyografik bulguların negatif olduğu semptomatik hastalarda erken evrede tanı koymaktadır. AVN 'erken tanısı' için bildirilen MR duyarlıı̆ı̆ı \%88 ila \%100 arasında değişmektedir ve çökme öncesi lezyonların saptanmasında da altın standart tanı yöntemidir. ${ }^{[10]}$ Özellikle kontrastlı çekilen MR ile çok yüksek riskli asemptomatik hastalarda veya bir kalçası AVN olan hastanın diğer kalçasında erken evrede tanı konulabilir. [11]

Avasküler nekroz (osteonekroz) bölgesindeki dokular MR'de farklı sinyal özellikleri gösterebilmektedir. MR'de saptanan ilk anormal bulgu, nekrotik ve normal alan arasındaki kavşakta görülen bant benzeri lezyondur. T1 ağırlıklı sekanslar üzerinde düşük sinyal yoğunluğuna sahip sınırlı bir subkondral "bant benzeri" bir lezyonun varlığı AVN için patognomonik olarak kabul edilir (Şekil 2). ${ }^{[12]} \mathrm{T} 2$ ağırlıklı sekansta ise 'çift çizgi bulgusu' (double line sign) AVN için patognomoniktir (Şekil 3). ${ }^{[10]}$ Dışta reaktif sklerotik kemiği temsil eden düşük sinyal yoğunluğu ve içte vasküler granülasyon dokusunu temsil eden yüksek sinyal yoğunluğundan oluşur. 


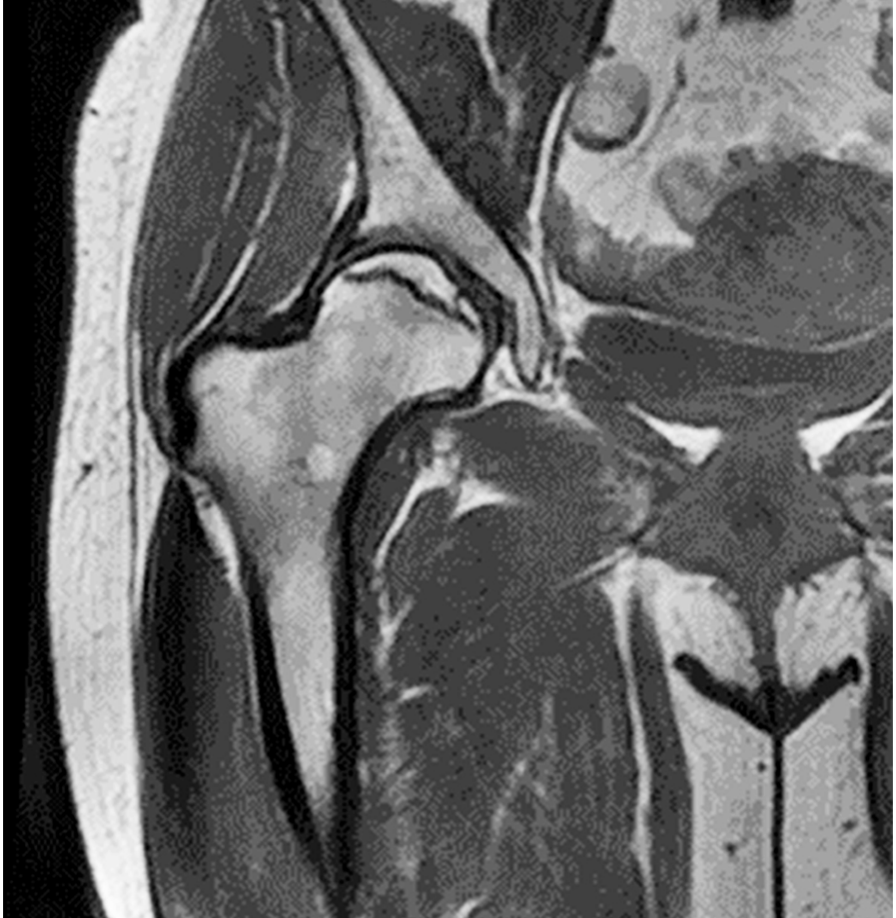

Şekil 2. T1 ağırlıklı sekansta subkondral "bant benzeri” lezyon.

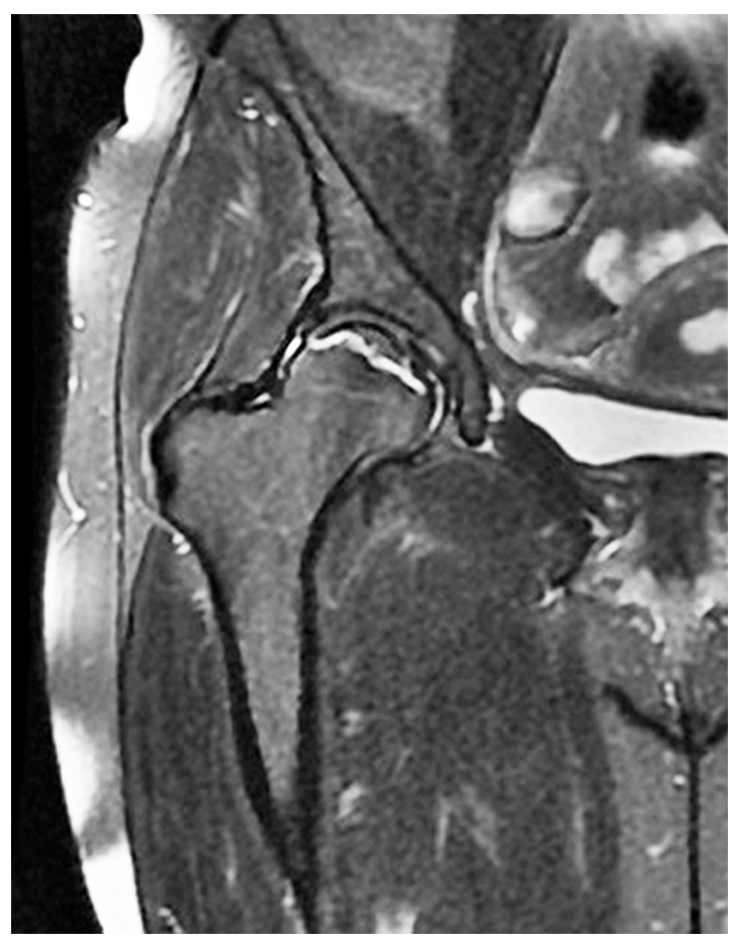

Şekil 3. T2 ağırlıklı sekansta AVN için patognomonik 'çift çizgi bulgusu' (double line sign).
Mitchell ve ark., T1 ve T2 ağırlıklı görüntülerde lezyonun merkezindeki sinyal özelliklerine göre dört AVN sınıfı tanımlamışlardır (Tablo 2). ${ }^{[12]}$ Radyografik evreleme ve prognozla ilişkili olmadığı için bu evreleme çok kullanılmamaktadır.

Ficat-Arlet sınıflaması yaygın kullanımına rağmen nekrozun boyutunu ve lokalizasyonunu dikkate almaz. Steinberg (Pennsylvania Üniversitesi), FicatArlet sınıflamasını kemik sintigrafisi ve MR bulgularını da dâhil ederek, başın eklem tutulum miktarını da içerecek şekilde genişletmiştir. ${ }^{[13]}$ Daha sonra geliştirilen ARCO (Association Research Circulation Osseous) sınıflaması Streinberg sınıflamasını esas almakla birlikte, sınıflamaya lokalizasyonu da eklemiştir (Tablo 3). ${ }^{[14]}$ Tüm sınıflandırma sistemlerinde en kritik nokta femur başının küresel kontur kaybı yani eklem yüzeyindeki çökmedir.

Radyolojik yöntemler erken tanı koyma ve tedavi seçimi dışında prognoz konusunda da fikir verebilmektedir. Femur başının şeklinin bütünlüğü, lezyonun genişliği ve lokalizasyonu, femur başında çökme, kemik iliği ödemi ve asetabular tutulum prognostik önemi olan bulgulardır.

Eklem yüzey tutulumu daha büyük olan lezyonların çökme olasılığı daha yüksektir. Eklem yüzeyinin tutulumu AP ve lateral radyografilerde lezyonun açısal (Kerboul angle) arkının ölçülmesiyle hesaplanabilir (Şekil 4). ${ }^{[15]} \mathrm{Bu}$ ölçüm MR'de yapılarak modifiye
Tablo 2. Mitchell MR evrelemesi[12]

\begin{tabular}{cccl}
\hline Sınıf & T1 & T2 & Tanım \\
\hline A & Parlak & Orta & Yağ sinyali \\
B & Parlak & Parlak & Kan sinyali \\
C & Orta & Parlak & Sivı ya da ödem sinyali \\
D & Koyu & Koyu & Fibrozis sinyali
\end{tabular}

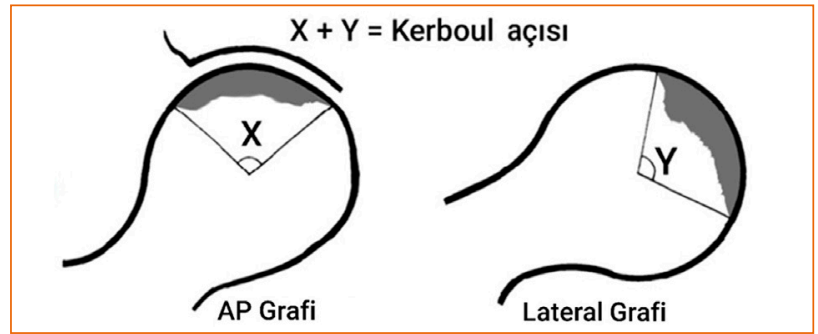

Şekil 4. Kerboul açısı. 
Tablo 3. Avasküler nekrozda sınıflamalar

\begin{tabular}{|c|c|c|c|}
\hline & Ficat-Arlet & Steinberg/U Penn & ARCO \\
\hline Evre 1 & $\begin{array}{l}\text { - Düz grafi normal veya minör } \\
\text { osteopeni. } \\
\text { - MR: Ödem. } \\
\text { - Kemik sintigrafisi (Bone Scan): Artmış } \\
\text { tutulum. } \\
\text { - Klinik semptomlar: Kasıkta tipik ağrı. }\end{array}$ & - Normal röntgen. & $\begin{array}{l}\text { - Hastalar semptomatik veya asemptomatik } \\
\text { olabilir. } \\
\text { - Röntgen ve BT bulguları belirgin değil. } \\
\text { - MR ve Bone Scan sonuçlarına bakılarak } \\
\text { AVN'den bahsedilebilir. } \\
\text { - Histolojik bulgular anormal. }\end{array}$ \\
\hline Evre 2 & $\begin{array}{l}\text { - Düz grafi: Mixed osteopeni, ve/veya } \\
\text { skleroz ve/veya subkondral kistler, } \\
\text { subkondral lusensi yok. } \\
\text { - MR: Coğrafi defekt. } \\
\text { - Bone Scan: Artmış tutulum. } \\
\text { - Klinik Semptomlar: Ağrı ve katılık. }\end{array}$ & $\begin{array}{l}\text { - Kistik ve sklerotik radyolojik } \\
\text { değişiklikler. }\end{array}$ & $\begin{array}{l}\text { - Hasta semptomatik. } \\
\text { - Düz grafi bulguları anormal ve osteopeni, } \\
\text { osteoskleroz ve kistleri içerir. } \\
\text { - Subkondral radyolusensi yok. } \\
\text { - MR bulguları tanısal. }\end{array}$ \\
\hline Evre 3 & $\begin{array}{l}\text { - Düz grafi: Hilâl bulgusu ve sonunda } \\
\text { kortikal kollaps. } \\
\text { - MR: Düz grafi ile aynı. } \\
\text { - Klinik Semptomlar: Ağrı ve katılık +/- } \\
\text { dize yayılım ve topallama. }\end{array}$ & $\begin{array}{l}\text { - Femur başında düzleşme } \\
\text { olmadan subkondral kollaps } \\
\text { "hilâl bulgusu". }\end{array}$ & $\begin{array}{l}\text { - Femur başında kollaps, "hilâl bulgusu”, } \\
\text { eklem aralığında daralma yok. }\end{array}$ \\
\hline IIIA & - & - & $\begin{array}{l}\text { • Hilâl eklem yüzeyinin \%15'inden az. } \\
<3 \text { mm kollaps }\end{array}$ \\
\hline IIIB & - & - & $\begin{array}{l}\text { - Hilâl eklem yüzeyinin \%15-30 arasında. } \\
>3 \text { mm kollaps }\end{array}$ \\
\hline IIIC & - & - & $\begin{array}{l}\text { - Hilâl eklem yüzeyinin \%30'undan fazla. } \\
>3 \text { mm kollaps }\end{array}$ \\
\hline Evre 4 & $\begin{array}{l}\text { - Düz grafi: Sekonder dejeneratif } \\
\text { değişikliklerle beraber geç evre } \\
\text { hastalık. } \\
\text { - MR: Düz grafi ile aynı. } \\
\text { - Klinik semptomlar: Ağrı ve topallama. }\end{array}$ & $\begin{array}{l}\text { - Subkondral kollaps, femur } \\
\text { başında düzleşme, normal } \\
\text { eklem aralığı. }\end{array}$ & $\begin{array}{l}\text { - Femur başında düzleşme veya kollaps. } \\
\text { - Eklem aralığı düzensiz olabilir. } \\
\text { - BT düz grafiye kıyasla daha duyarlı. }\end{array}$ \\
\hline Evre 5 & - & $\begin{array}{l}\text { - Asetabulumu içeren veya } \\
\text { içermeyen şekilde eklem } \\
\text { aralığında daralma. }\end{array}$ & $\begin{array}{l}\text { Radyolojik bulgular; eklem aralığında } \\
\text { daralma, asetabulumda skleroz ile birlikte } \\
\text { osteoartrit ve marjinal osteofitler. }\end{array}$ \\
\hline Evre 6 & - & $\begin{array}{l}\text { - Ileri dejeneratif değişiklikler, } \\
\text { sekonder osteoartrit. }\end{array}$ & $\begin{array}{l}\text { - Femur başı ve ekleminin ileri yıkımını } \\
\text { gösteren radyolojik bulgular. }\end{array}$ \\
\hline
\end{tabular}

edilmiştir (modifiye Kerboul angle). Koronal ve sagittal planda ölçülen açıların toplanmasıyla elde edilen kombine nekrotik alanın boyutu $190^{\circ}$ altında olduğunda çökme açısından düşük riskli iken, $240^{\circ}$ üzerinde ise yüksek riskli grupta yer alır. ${ }^{16]}$ Ayrıca koronal ve aksiyel kesitler kullanılarak etkilenen nekrotik alanın hacmi hesaplanabilir. Femur başının \%15'inden az hacim kaplayan nekrotik alanlar küçük, \%30'dan büyük hacim kaplayan nekrotik alanlar ise büyük lezyonlar olarak tanımlanmaktadır (Şekil 5). ${ }^{[17]}$

Femur başta 2 mm'den fazla çökme kötü prognoz göstergesidir ${ }^{[18]}$ ve eklem koruyucu tedavilerin bu hastalarda başarısız olduğu gösterilmiştir. ${ }^{[6,9]}$ Bununla birlikte MR görüntülemede asetabular tutulum varlığı kötü prognozla ilişkilidir ve femur başına yönelik kurtarıcı girişimlerin başarısızlığı ile beraberdir. ${ }^{[19]}$
Femur başının medial anterosuperior kısmıyla sınırlı küçük lezyonlar ve subkondral sınırlarla temas etmeyen lezyonlar iyi prognozludur ve konservatif olarak izlenebilir. ${ }^{[10]}$

Kemik iliği ödeminin varlığı büyük oranda semptomların artmasıyla ilişkilidir ve yapısal hasarın artarak çökmeye doğru ilerlediğini gösteren bir bulgudur. ${ }^{[10,20]}$ Kemik iliği ödeminin kalça ağrısının başlaması veya kötüleşmesi için en önemli prognostik faktör olduğu belirtilmiştir. ${ }^{[21]}$ En sık evre 3'de görülür. Core dekompresyonunda başarısızlık ve total kalça artroplastisi gerektiren dejeneratif artrite ilerleme ile ilişkili olduğu gösterilmiştir. ${ }^{[22]}$

Bununla birlikte kalça avasküler nekrozu olan hastaların \%30-50'sinde intertrokanterik bölgeye uzanan kemik iliği ödemi görülebilir ${ }^{[0]}$ ve bu durum geri 


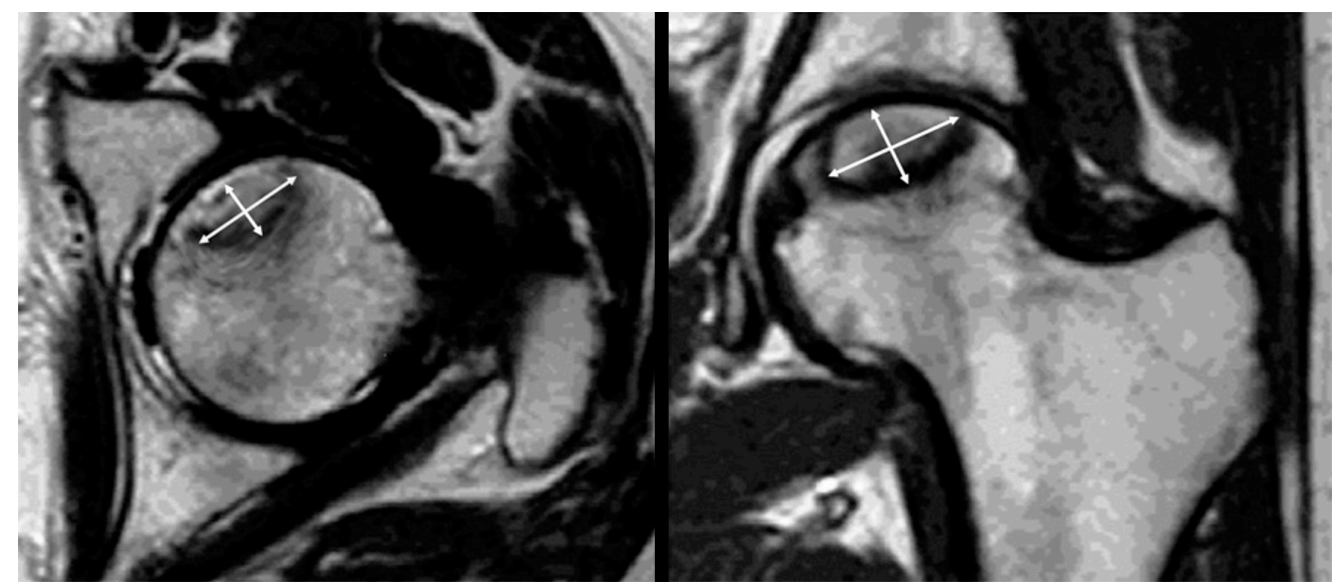

Şekil 5. Koronal ve aksiyel kesitlerde nekrotik alanın hacmi arttıkça prognoz kötüleşir.

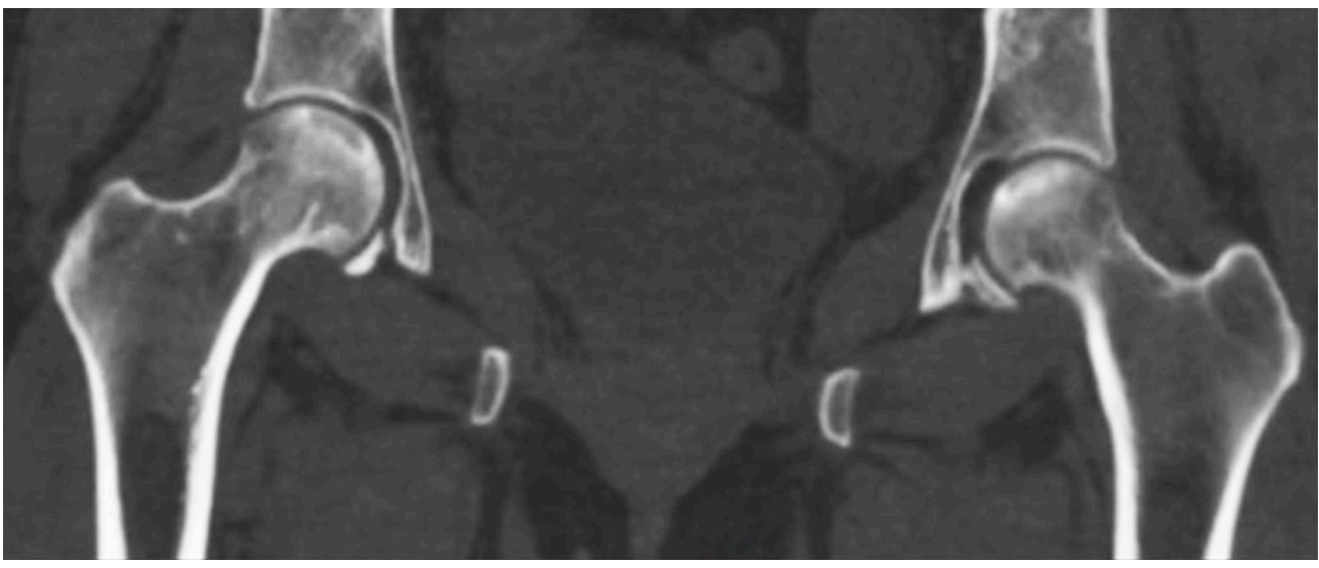

Şekil 6. Bilateral avasküler nekroz BT görünümü.

dönüşümlü bir durum olan kalçanın geçici (transient) osteoporozu ile karışabilir. Bu ikisinin ayrımı önemlidir çünkü transient osteoporoz kendi kendini sınırlayan ve eklem koruyucu cerrahiler gerektirmeyen bir durumdur. Transient osteoporozun AVN ile ilişkisi tartışmalıdır. Avasküler nekrozun hastalığın başlangıcında yaygın kemik iliği ödemi olarak başladığı ve bunu takiben AVN'ye özgü fokal lezyonların geliştiği teorisi ileri sürülmüştür. Ancak avasküler nekrozda kemik iliği ödemi tipik olarak nekrotik hacimin arttığı, eklem çökmesinin olduğu ve ağrının kötüleştiği ileri evrelerde görülür (evre 3). ${ }^{[10,21,22]}$ Transient osteoporozda ödem hastalığın erken aşmasında görülür ve kendini sınırlayarak 6-10 ay içinde düzelmesi beklenir, avasküler nekrozdaki gibi progresif olarak kötüleşmez. ${ }^{[2]}$

Transient osteoporozda büyük oranda tek taraflı tutulum varken (sıklıkla sol kalça), avasküler nekroz $\% 80$ 'den fazla bilateral tutulum gösterir. ${ }^{[2]}$

Subkondral anormallikler, T1'de parlak bant benzeri lezyonlar ve T2'deki çift cizgi işareti transient osteoporozda görülmez; homojen, düzgün sınırlı ve diffüz bir ödem görülür. Bazen yetmezlik kırıklarına bağlı minimal çizgi şeklinde subkonral lezyonlar görülebilir.

Bununla birlikte birbirinden ayrı klinik durumlar olmasına rağmen geçici osteoporoz zemininde avasküler nekroz gelişebilir. Turner ve ark., femur boynunda ve intertrokanterik bölgede yaygın kemik iliği ödemi ile başvuran hastaların daha sonra femur başında osteonekroz ile uyumlu fokal lezyonlar geliştirebileceğini göstermiştir. ${ }^{[23]}$

Eklem içi effüzyonun ağrı ile ilişkisi tartışmalıdır ancak kemik iliği ödemi ve artmış nekrotik hacimle birlikte ağrı ile ilişkisi gösterilmiştir. ${ }^{[10]}$

\section{BILGISAYARLI TOMOGRAFI (BT)}

BT, AVN'ye bağlı anormallikleri saptamada radyografiden daha duyarlı olmakla birlikte AVN tanısı için rutin olarak önerilmez (Şekil 6). ${ }^{[5]}$ Nekrotik değişiklikleri 
daha ileri evrelerde gösterir ve erken evrelerde MR'den daha az duyarlıdır. [24] BT özellikle çökme öncesi geç evre osteonekroz ile erken çökme dönemi arasındaki dönemde yararlı olabilir, çünkü femur başındaki subkondral kırıkların tespitinde MR'den daha iyi sonuç verdiği bildirilmiştir. ${ }^{[25]} \mathrm{Bu}$ nedenle $\mathrm{MR}$ şüpheli veya kontrendike olduğunda subkondral kırık varlığını dışlamak için kullanılabilir. BT ayrıca ameliyat sonrası takiplerde kullanılmaktadır.

\section{KEMIK SINTIGRAFisi}

Osteonekrozun erken evresinde değerli tanı yöntemi olmakla birlikte duyarlılığı ve özgüllüğü düşüktürr. ${ }^{[3,6]}$ Vücutta avasküler nekrozun taraması ve multifokal lezyonların tanımlanması için kullanılabilmektedir ancak rutin değildir. ${ }^{[26]}$ Tanı yöntemi olarak erken evrelerde MR'nin kontrendike olduğu durumlarda önerilmektedir.

\section{KAYNAKLAR}

1. Murphey MD, Foreman KL, Klassen-Fischer MK, Fox MG, Chung EM, Kransdorf MJ. From the radiologic pathology archives imaging of osteonecrosis: radiologic-pathologic correlation. Radiographics 2014;34(4):1003-28. Crossref

2. Çevikol C. Avasküler nekrozda manyetik rezonans görüntüleme. TOTBiD Derg 2010;9(1):7-18. https:// docplayer.biz.tr/22032470-Avaskuler-nekrozda-manyetikrezonans-goruntuleme.html

3. Imhof $\mathrm{H}$, Breitenseher $\mathrm{M}$, Trattnig $\mathrm{S}$, Kramer J, Hofmann S, Plenk H, Schneider W, Engel A. Imaging of avascular necrosis of bone. Eur Radiol 1997;7(2):180-6. Crossref

4. Ege R. Femur başı avasküler nekrozu. İçinde: Ege R, editör. Kalça Cerrahisi ve Sorunları. Ankara: Türk Hava Kurumu Basımevi; 1996. s.752-67.

5. Manenti G, Altobelli S, Pugliese L, Tarantino U. The role of imaging in diagnosis and management of femoral head avascular necrosis. Clin Cases Miner Bone Metab 2015;12(Suppl 1):31-8. Crossref

6. Özdemir H, Baloğlu M. Femur başının avasküler nekrozu: Tanı ve tedavisi. TOTBiD Derg 2010;9(1):41-51. http:// dergi.totbid.org.tr/files/9_1/13.pdf

7. Jawad MU, Haleem AA, Scully SP. In brief: Ficat classification: avascular necrosis of the femoral head. Clin Orthop Relat Res 2012;470(9):2636-9. Crossref

8. Gross TP, Liu F. Is there added risk in resurfacing a femoral head with cysts? J Orthop Surg Res 2011;6(1):55. Crossref

9. Petek D, Hannouche D, Suva D. Hip Open Access Open Access license Osteonecrosis of the femoral head: pathophysiology and current concepts of treatment. EFORT Open Rev 2019;4(3):85-97. Crossref

10. Karantanas $\mathrm{AH}$, Drakonaki EE. The role of MR imaging in avascular necrosis of the femoral head. Semin Musculoskelet Radiol 2011;15(3):281-300. Crossref

11. Esnick D, Sweet DE and Madewell JE. Osteonecrosis and osteochondrosis. In: Resnick D, Kransdorf MJ, editors. Bone and Joint Imaging, 3rd ed. Philadelphia: Elsevier Saunders; 2005. p.1067-107.
12. Mitchell DG, Rao VM, Dalinka MK, Spritzer CE, Alavi A, Steinberg ME, Fallon M, Kressel HY. Femoral head avascular necrosis: correlation of MR imaging, radiographic staging, radionuclide imaging, and clinical findings. Radiology 1987;162(3):709-15. Crossref

13. Steinberg ME, Brighton CT, Corces A, Hayken GD, Steinberg DR, Strafford B, Tooze SE, Fallon M. Osteonecrosis of the femoral head. Results of core decompression and grafting with and without electrical stimulation. Clin Orthop Relat Res 1989;(249):199-208. Crossref

14. Gardeniers JWM. ARCO Committee on Terminology and Staging. Report on the committee meeting at Santiago de Compostella. ARCO Newsletter 1993;5(2):79-82. https:// www.arco-intl.org/Newsletters/Gardeniers-1993-5-2/ Gardeniers-1993.htm

15. Kerboul M, Thomine J, Postel M, D'Aubigné RM. The conservative surgical treatment of idiopathic aseptic necrosis of the femoral head. J Bone Joint Surg Br 1974;56-B(2):2916. Crossref

16. Ha YC, Jung WH, Kim JR, Seong NH, Kim SY, Koo KH. Prediction of collapse in femoral head osteonecrosis: a modified Kerboul method with use of magnetic resonance images. J Bone Joint Surg Am 2006;88(Suppl 3):35-40. Crossref

17. Steinberg ME, Bands RE, Parry S, Hoffman E, Chan T, Hartman KM. Does lesion size affect the outcome in avascular necrosis? Clin Orthop Relat Res 1999;367:262-71. Crossref

18. Ficat RP, ArletJ. Functional investigation of bone under normal conditions. Ischemia and Necrosis of Bone. Hungerford DS, editor. Baltimore: Williams and Wilkins; 1980.

19. Aldridge 3rd JM, Urbaniak JR. Avascular necrosis of the femoral head: etiology, pathophysiology, classification, and current treatment guidelines. Am J Orthop (Belle Mead NJ) 2004;33(7):327-32. https://pubmed.ncbi.nlm.nih. gov/15344574/

20. Ito $H$, Matsuno $T$, Minami A. Relationship between bone marrow edema and development of symptoms in patients with osteonecrosis of the femoral head. AJR Am J Roentgenol 2006;186(6):1761-70. Crossref

21. lida S, Harada Y, Shimizu K, Sakamoto M, Ikenoue S, Akita $\mathrm{T}$, Kitahara $\mathrm{H}$, Moriya $\mathrm{H}$. Correlation between bone marrow edema and collapse of the femoral head in steroid-induced osteonecrosis. AJR Am J Roentgenol 2000;174(3):735-43. Crossref

22. Radke S, Kirschner S, Seipel V, Rader C, Eulert J. Magnetic resonance imaging criteria of successful core decompression in avascular necrosis of the hip. Skeletal Radiol 2004;33(9):51923. Crossref

23. Turner DA, Templeton AC, Selzer PM, Rosenberg AG, Petasnick JP. Femoral capital osteonecrosis: MR finding of diffuse marrow abnormalities without focal lesions. Radiology 1989;171(1):135-40. Crossref

24. Conway WF, Totty WG, McEnery KW. CT and MR imaging of the hip. Radiology 1996;198(2):297-307. Crossref

25. Stevens K, Tao C, Lee SU, Salem N, Vandevenne J, Cheng C, Neumann G, Valentin-Opran A, Lang P. Subchondral fractures in osteonecrosis of the femoral head: comparison of radiography, CT, and MR imaging. AJR Am J Roentgenol 2003;180(2):363-8. Crossref

26. Mont MA, Hungerford DS. Non-traumatic avascular necrosis of the femoral head. J Bone Joint Surg Am 1995;77(3):45974. Crossref 